\title{
Probing Water Interactions and Vacancy Production on Gadolinia-Doped Ceria Surfaces Using Electron Stimulated Desorption
}

\author{
Haiyan Chen, ${ }^{\dagger}$ Alex Aleksandrov, ${ }^{\dagger}$ Yanfeng Chen, ${ }^{\dagger}$ Shaowu Zha, ${ }^{\ddagger}$ Meilin Liu,,${ }^{\ddagger}$ and \\ Thomas M. Orlando*,, \\ School of Chemistry and Biochemistry, and School of Materials Science and Engineering, \\ Georgia Institute of Technology, Atlanta, Georgia 30332
}

Received: December 22, 2004; In Final Form: April 6, 2005

\begin{abstract}
Polycrystalline gadolinia-doped ceria (GDC) surfaces were studied using low-energy $(5-400$ eV) electron stimulated desorption (ESD). $\mathrm{H}^{+}, \mathrm{O}^{+}$, and $\mathrm{H}_{3} \mathrm{O}^{+}$were the primary cationic desorption products with $\mathrm{H}^{+}$as the dominant channel. $\mathrm{H}^{+}, \mathrm{H}_{3} \mathrm{O}^{+}$, and $\mathrm{O}^{+}$have a $22 \mathrm{eV}$ threshold followed by a yield change around $40 \mathrm{eV}$. $\mathrm{H}^{+}$also has an additional yield change $\sim 75 \mathrm{eV}$ and $\mathrm{O}^{+}$has an additional change $\sim 150 \mathrm{eV}$. The $\mathrm{O}^{+} \mathrm{ESD}$ yield change $\sim 150 \mathrm{eV}$ may indicate bond breaking of $\mathrm{Gd}-\mathrm{O}$ and the involvement of oxygen vacancies. The $\mathrm{H}^{+}$and $\mathrm{H}_{3} \mathrm{O}^{+}$threshold data collectively indicate the presence of hydroxyl groups and chemisorbed water molecules on the GDC surfaces. ESD temperature dependence measurements show that the interaction of water with GDC surface defect sites, mainly oxygen vacancies, influences the desorption of $\mathrm{H}^{+}, \mathrm{O}^{+}$, and $\mathrm{H}_{3} \mathrm{O}^{+}$. The temperature dependence of the $\mathrm{O}^{+}$ESD at $400 \mathrm{eV}$ incident electron energy yields a $0.21 \mathrm{eV}$ activation energy. This is close to the energy needed for oxygen vacancy production next to a pair of $\mathrm{Ce}^{3+}$ on a $\mathrm{CeO}_{2}$ surface. These results may indicate a correlation between the $\mathrm{O}^{+}$ESD yield and oxygen vacancy density on GDC surfaces and a potential correlation of $\mathrm{O}^{+}$ESD and GDC ionic conductivity.
\end{abstract}

\section{Introduction}

Solid oxide fuel cells (SOFCs) are highly efficient and environmentally benign energy conversion devices, ${ }^{1-5}$ and polycrystalline $\mathrm{Ce}_{0.9} \mathrm{Gd}_{0.1} \mathrm{O}_{2-\delta}(\mathrm{GDC})$ is considered to be one of the most promising electrolytes for low-temperature (500$600^{\circ} \mathrm{C}$ ) SOFCs. GDC has been used as the electrolyte for lowtemperature SOFCs and as part of composite electrodes to facilitate ionic conduction within the electrodes. To understand the mechanisms of defect mediated ion conduction and reactions at a fundamental level, it is critical to understand the GDC surface defects that play significant roles in these processes.

Gadolinia-doped ceria has the fluorite structure of $\mathrm{CeO}_{2}$ with gadolinium atoms occupying a fraction of cerium lattice sites. Therefore, the knowledge of the structural and electronic characteristics of $\mathrm{CeO}_{2}$ surfaces is relevant to that of GDC. For low-index surfaces of $\mathrm{CeO}_{2},(111)$ is the most stable. Upon annealing to high temperature, $\mathrm{CeO}_{2}$ (110) and $\mathrm{CeO}_{2}$ (001) form $\mathrm{CeO}_{2}$ (111) faceted surfaces. ${ }^{6}$ On the $\mathrm{CeO}_{2}$ (111) surface, clustering of oxygen vacancies was theoretically predicted and experimentally verified. ${ }^{7}$ In $\mathrm{CeO}_{2}$, all four valence electrons of cerium, $6 \mathrm{~s}^{2} 5 \mathrm{~d}^{1} 4 \mathrm{f}^{1}$, nominally leave the host atoms and transfer into the $\mathrm{p}$ bands of the oxygen atoms, while, in $\mathrm{Ce}_{2} \mathrm{O}_{3}$, the $\mathrm{Ce}$ $4 \mathrm{f}$ electrons are fully localized. According to theory, it requires $4.55 \mathrm{eV}$ to form an oxygen vacancy in pure $\mathrm{CeO}_{2}$ and only $0.26 \mathrm{eV}$ if vacancy production occurs next to a pair of $\mathrm{Ce}^{3+}$ atoms embedded into the $\mathrm{CeO}_{2}$ matrix. ${ }^{8}$ The oxygen vacancy formation process is facilitated by a simultaneous transfer of two electrons into the localized f-level traps on two cerium

* To whom correspondence should be addressed. Phone: (+1) 404-894 4012. FAX: (+1) 404-894-7452. E-mail: Thomas.Orlando@chemistry.gatech. edu.

School of Chemistry and Biochemistry.

$\doteqdot$ School of Materials Science and Engineering. atoms, which therefore changes their valence from $4+$ to $3+$. The localization and delocalization of $\mathrm{Ce} 4 \mathrm{f}$ electrons are involved in the formation and migration of vacancies. Oxygen vacancy pairs, which are probably important for $\mathrm{O}_{2}$ uptake and release, are evidently easier to form on the $\mathrm{CeO}_{2}$ (111) surfaces.

Similarly, for gadolinia-doped ceria, molecular dynamics simulation showed that $\mathrm{Gd}$ ions are apt to form a $\mathrm{Gd}^{3+-}$. vacancy $-\mathrm{Gd}^{3+}$ cluster. Cerium ions tend not to be adjacent to a vacancy. ${ }^{9}$ This segregation effect in $\mathrm{Ce}_{0.8} \mathrm{Gd}_{0.2} \mathrm{O}_{2-\delta}$ was observed and characterized by a combination of $Z$-contrast imaging and electron energy loss spectroscopy (EELS). ${ }^{10}$ The composition profile obtained by EELS showed an excess of oxygen vacancies and gadolinium ions in the grain boundary core. This structural feature determines the importance of GDC grain boundaries in ionic conduction as well as in surface and interface reactions. Indeed, it has been found that the smaller the grain size, the higher the grain boundary electrical conductivity. ${ }^{11}$

Less work has been reported concerning surface reactions on GDC. Thus far, only the oxygen surface exchange reaction has been investigated using isotope exchange depth profiling (IEDP) via secondary ion mass spectrometry (SIMS). ${ }^{12-15}$ With IEDP-SIMS, the activation energy for the oxygen surface exchange reaction was found to be temperature-dependent, around $1 \mathrm{eV}$ for temperatures below 923 or $973 \mathrm{~K}$ and $2.4-3.3$ $\mathrm{eV}$ at higher temperatures. The mechanisms leading to this temperature dependence are yet to be understood at an electronic level and have not been investigated in detail using other surface specific techniques.

Electron stimulated desorption (ESD) is a surface analysis technique that can probe adsorbates and their interactions with the surface through the characterization of desorbed ionic or neutral species. ${ }^{16,17}$ The threshold energy for producing desorbed species as well as their kinetic energy distributions are of 


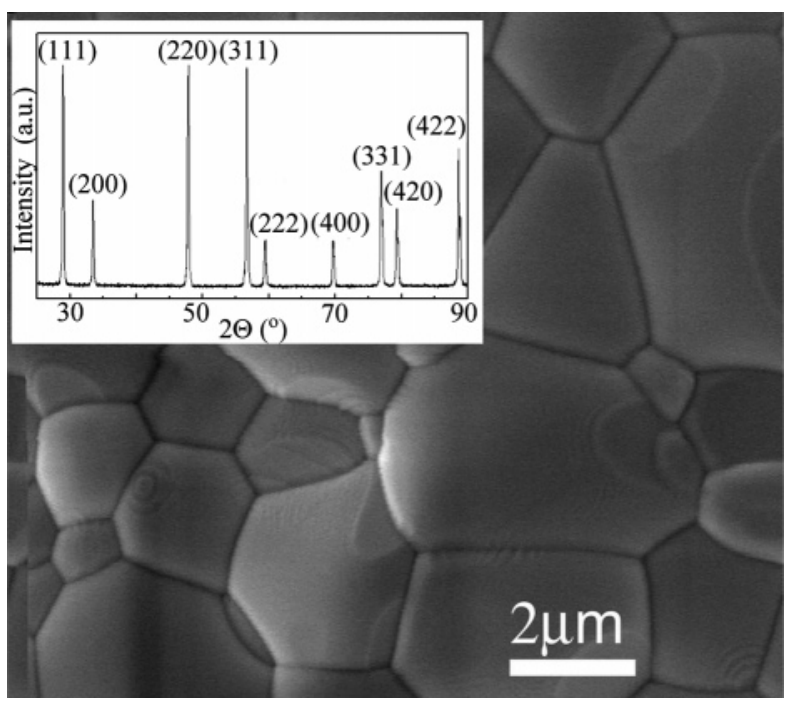

Figure 1. SEM image of the GDC surface morphology. The inset is the XRD pattern of a sintered GDC pellet, indicating a fluorite structure. Note the defective grain boundaries and triple junctions on the surface.

importance in identifying the specific site of adsorption. Since defects or local disorder on a surface may act as the trapping sites of electronic excitations, they can serve as preferential sites for desorption. Therefore, ESD can yield direct information regarding defects and their role in surface reactions critical to the electrochemical performances of SOFCs.

To explain the ESD of cations from metal oxides, Knotek and Feibelman $(\mathrm{K}-\mathrm{F})$ proposed a model based on interatomic Auger neutralization of holes produced in the core levels of surface atoms. ${ }^{18}$ The interatomic Auger decay of the core hole creates a positive ion at an initially negative ion site, and the expulsion of the positive ion results from the reversal of the Madelung potential. A more generalized Auger-stimulated desorption model has extended the $\mathrm{K}-\mathrm{F}$ model to less ionic and covalent systems. ${ }^{19}$

In this paper, we present a study of electron stimulated desorption of cations from polycrystalline gadolinia-doped ceria surfaces. Section II describes the experimental approaches. The results include threshold and temperature dependencies of ESD cation yields and are presented in section III. Details of the ESD mechanisms, the importance of water interactions with the surface, and the significance of correlations between $\mathrm{O}^{+}$ESD and vacancy formation are also discussed in section III. Finally, conclusions are given in section IV.

\section{Experimental Section}

(II.a) Sample Preparation and Characterization. The $\mathrm{Ce}_{0.9} \mathrm{Gd}_{0.1} \mathrm{O}_{2-\delta}$ (GDC) powder was prepared using a glycinenitrate process as described elsewhere. ${ }^{1}$ The GDC pellet used in this experiment was cold-pressed from the powder and then fired at $1550{ }^{\circ} \mathrm{C}$ for $5 \mathrm{~h}$ in air to achieve a greater than $95 \%$ relative density. The dimensions of the GDC pellet were about $10 \times 6 \times 1 \mathrm{~mm}^{3}$. X-ray diffraction (XRD, PW-1800 system, with $\mathrm{Cu} \mathrm{K \alpha}$ radiation operated at $40 \mathrm{kV}$ and $30 \mathrm{~mA}$ ), and scanning electron microscopy (SEM, Hitachi S-800) studies were performed on sintered GDC pellets. As shown in Figure 1, typical XRD patterns of a GDC sample indicate a singlephase fluorite structure. The SEM image of the surface morphology of an as-sintered GDC sample shows that grain size varies from 1 to $5 \mu \mathrm{m}$, and the sample has a significant number of grain boundaries.

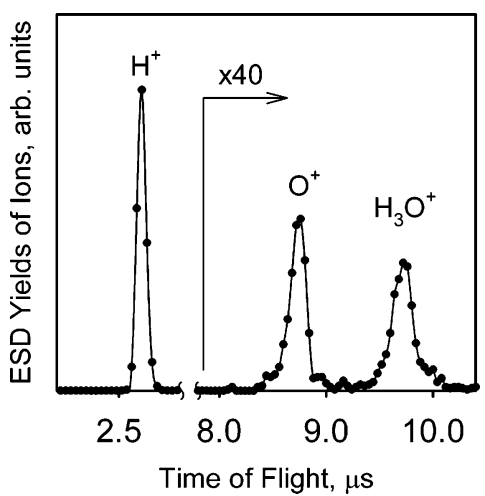

Figure 2. Typical ESD-TOF spectrum of ions emitted from a GDC surface during pulsed $400 \mathrm{eV}$ electron irradiation. The $\mathrm{H}^{+}$yield is significantly larger than the $\mathrm{O}^{+}$and $\mathrm{H}_{3} \mathrm{O}^{+}$yields.

(II.b) Electron Stimulated Desorption. Details of the electron stimulated desorption (ESD) measurement system have been discussed in a previous paper. ${ }^{20}$ The system consists of an ultrahigh vacuum chamber (base pressure, $2 \times 10^{-10}$ Torr) equipped with a rotatable sample holder, a computer-controlled button heater, a quadrupole mass spectrometer (QMS), a timeof-flight (TOF) mass spectrometer, a pulsed low-energy electron gun, and a calibrated dosing system.

The GDC sample was annealed to $400{ }^{\circ} \mathrm{C}$ to remove all contaminants from the surface. The sample was irradiated by the pulsed electron beam at $1000 \mathrm{~Hz}$ with an electron flux of $10^{14}$ electrons $/\left(\mathrm{cm}^{2} \mathrm{~s}\right)$ during a given pulse or time-averaged currents of $200 \mathrm{pA}$ to a few nanoampere. Emitted cations were collected by applying a $-100 \mathrm{~V}$ pulsed extraction potential to the TOF front lens assembly just after the end of the electron pulse to avoid the influence of the potential field on the incident electron energy. A typical cation ESD-TOF spectrum is displayed in Figure 2, showing $\mathrm{H}^{+}, \mathrm{O}^{+}$, and $\mathrm{H}_{3} \mathrm{O}^{+}$. No other ions were observed, indicating the cleanliness of the surface. For temperature-dependent ESD measurements, the QMS (with its ionizer turned off) was employed as the mass analyzer. All ions were detected using pulse counting and a transient digitizer.

In our previous ESD study on GDC, ${ }^{20}$ it was found that the ESD ion yields were dependent on the electron beam induced surface charging. At higher electron energy, the surface was positively charged. For lower energies, the charge buildup was negative and the ion yields dropped exponentially with the negative surface potential. To avoid this dramatic influence of negative surface charging on ion yields, two special experimental procedures were undertaken: (1) a short electron pulse length (500 ns) and a short time for signal averaging were employed; (2) before obtaining ESD-TOF spectra, the sample was irradiated with a $400 \mathrm{eV}$ pulsed electron beam for $60 \mathrm{~s}$. This assured that the surface was not negatively charged. Three ESD-TOF spectra were taken at each electron energy, and the average yield was used for threshold measurements. The yields were normalized to the electron beam current measured by a Faraday cup at each incident electron energy.

\section{Results and Discussion}

(III.a) Energy Dependence of Cation ESD Yields. Figure 3 and Figure 4 show the dependence of $\mathrm{H}^{+}, \mathrm{O}^{+}$, and $\mathrm{H}_{3} \mathrm{O}^{+}$ ESD from polycrystalline GDC on incident electron energy at room temperature. For $\mathrm{H}^{+}, \mathrm{H}_{3} \mathrm{O}^{+}$, and $\mathrm{O}^{+}$, there is a threshold at $22 \mathrm{eV}$, followed by a yield change around $40 \mathrm{eV}$. Figure 4 shows that $\mathrm{H}^{+}$has another yield change around $75 \mathrm{eV}$ and $\mathrm{O}^{+}$ has an additional yield change around $150 \mathrm{eV}$. Though the 


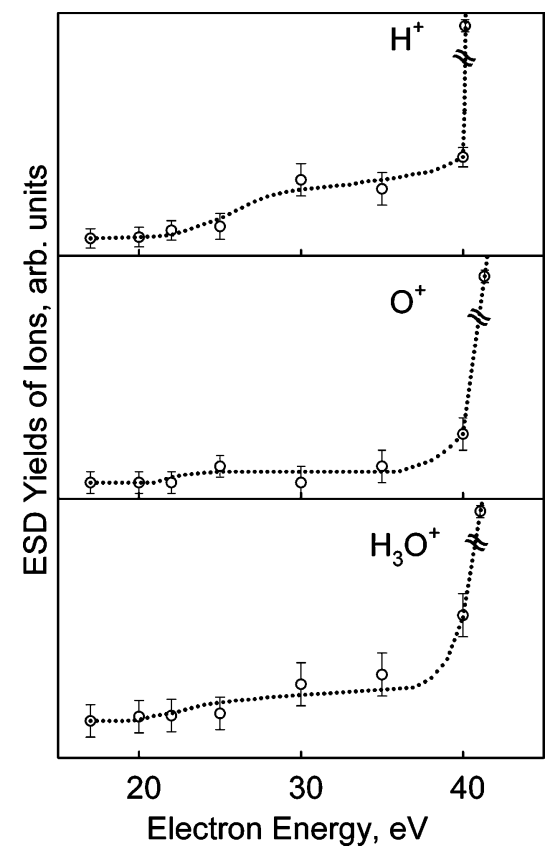

Figure 3. Dependence of ESD cation yields on incident electron energy in the range of 5-50 eV. The pulse length was $500 \mathrm{~ns}$, and the sample was at room temperature. Note the weak threshold at $22 \mathrm{eV}$ and a stronger threshold at $40 \mathrm{eV}$ for $\mathrm{H}^{+}, \mathrm{H}_{3} \mathrm{O}^{+}$, and $\mathrm{O}^{+}$.

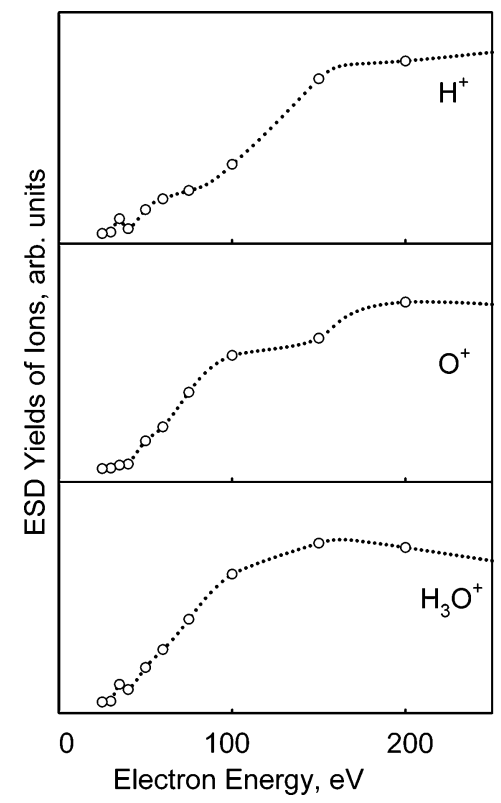

Figure 4. Dependence of ESD cation yields on incident electron energy. The pulse length was $500 \mathrm{~ns}$, and the sample was at room temperature. Note the yield change around $75 \mathrm{eV}$ for $\mathrm{H}^{+}$and $150 \mathrm{eV}$ for $\mathrm{O}^{+}$.

dependence of the ESD yields on electron energies of these three cations share certain thresholds, each ion depends on electron energy differently. This suggests that on GDC surfaces, the sites and species contributing to positive ion desorption are basically different.

(III.b) Electronic Structure of GDC. Knowledge of the electronic structure of GDC is important for understanding the observed threshold energies and desorption mechanisms. Unfortunately, there is only one X-ray photoelectron spectroscopy (XPS) survey scan of gadolinia-doped ceria thin films available in the literature. ${ }^{21}$ There are, however, studies on the electronic structure of cerium and gadolinium oxides. In the energy range we are interested in, an XPS study of $\mathrm{Gd}_{2} \mathrm{O}_{3}$ powder found

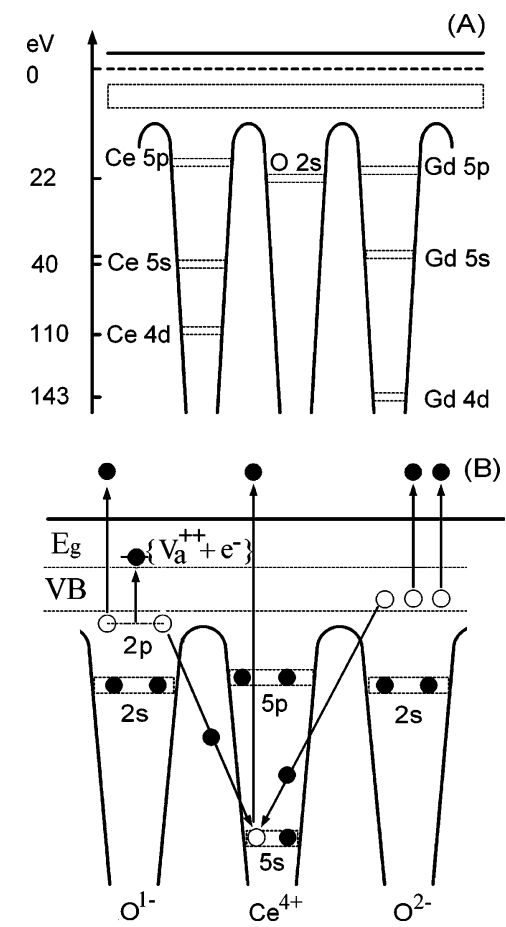

Figure 5. (A) Energy diagram of the core levels of cerium, gadolinium, and oxygen. The valance band level and band gap energy are unknown for GDC. (B) Illustration of the Knotek-Feibelman interatomic Auger decay mechanism for $\mathrm{O}^{+}$desorption from $\mathrm{O}^{2-}$ and an $\mathrm{O}^{-}$defect site. Shown is the $\mathrm{Ce} 5 \mathrm{~s}$ core hole production and subsequent Auger electron emission from the $\mathrm{O} 2 \mathrm{p}$ level in the valence band or from the $\mathrm{O} 2 \mathrm{p}$ level in the defect state. [ $\left.\mathrm{Va}^{2+}+\mathrm{e}-\right]$ denotes an electron trapped in an anion vacancy.

binding energies of 9.4, 23.0, 46.2, 142.5, and $147.9 \mathrm{eV}$ for $4 \mathrm{f}$, $5 \mathrm{p}, 5 \mathrm{~s}, 4 \mathrm{~d}_{5 / 2}$, and $4 \mathrm{~d}_{3 / 2}$ gadolinium core levels, respectively. ${ }^{22}$ The binding energy for the $\mathrm{O} 2 \mathrm{~s}$ level was found to be $27 \mathrm{eV}$. An ultraviolet photoelectron spectroscopy (UPS) study of the gadolinium oxidation process showed that the $\mathrm{O} 2 \mathrm{p}$ valence band and $\mathrm{O} 2 \mathrm{~s}$ core level for $\mathrm{Gd}_{2} \mathrm{O}_{3}$ were located at $\sim 6 \mathrm{eV}$ and $\sim 23.5$ $\mathrm{eV}$, respectively. ${ }^{23}$ The band gap of crystalline $\mathrm{Gd}_{2} \mathrm{O}_{3}$ is 5.3 $\mathrm{eV}$ according to Emeline et al. ${ }^{24}$ For $\mathrm{CeO}_{2}$, the binding energies for Ce $5 \mathrm{p}_{3 / 2}, 5 \mathrm{~s}$, and $4 \mathrm{~d}_{5 / 2}$ core levels are $18.0,36.8$, and 108.5 $\mathrm{eV}$, respectively, and $\mathrm{O} 2 \mathrm{p}$ is $\sim 5 \mathrm{eV} .{ }^{25}$ There is no $\mathrm{O} 2 \mathrm{~s}$ binding energy for $\mathrm{CeO}_{2}$ available, but the $\mathrm{O} 2 \mathrm{~s}$ level for $\mathrm{CeNbO}_{4}$ is $21.8 \mathrm{eV} . \mathrm{CeO}_{2}$ has a band gap of $6 \mathrm{eV} \cdot{ }^{26}$ Figure 5A is an energy diagram of the core levels of cerium, gadolinium, and oxygen in the energy range of this study, constructed by using the binding energies data of $\mathrm{CeO}_{2}$ and $\mathrm{Gd}_{2} \mathrm{O}_{3}$. Neither the band gap nor the energy level of the top of the valence band of GDC is available. Anion vacancies $\mathrm{V}_{\mathrm{a}}{ }^{2+}$ have unoccupied levels that are capable of trapping excited electrons from the valence band. As a result, the charge of an oxygen anion close to $\mathrm{V}_{\mathrm{a}}{ }^{2+}$ can be decreased from $\mathrm{O}^{2-}$ to $\mathrm{O}^{-}$, causing the decrease of $\mathrm{O} 2 \mathrm{p}$ local levels associated with $\mathrm{O}^{-}$.

(III.c) Threshold Values and ESD Mechanisms. (III.c.1) Desorption of $\mathrm{H}^{+}$. Hydrogen atoms may bond to cerium oxide surfaces in two different ways. The first is as hydroxyl groups which are most likely bonded to cerium cations. Soft X-ray photoemission spectroscopy and thermal desorption spectroscopy showed that, on reduced cerium oxide surfaces, water dissociates and forms hydroxyl. The formation of hydroxyl is found to be related to $\mathrm{Ce}^{3+}$ instead of $\mathrm{Ce}^{4+}$. Due to the presence of oxygen vacancies on GDC surfaces, a fraction of cerium atoms existing in the +3 oxidation states can lead to the formation of $\mathrm{Ce}-\mathrm{O}-\mathrm{H}$ on the surface. Similarly, hydroxyl 
groups can also bond to gadolinium atoms forming $\mathrm{Gd}-\mathrm{O}-\mathrm{H}$. The second form of hydrogen can be from chemically adsorbed water, as has been demonstrated on fully oxidized $\mathrm{CeO}_{2}$ surfaces by soft X-ray photoemission spectroscopy below $300 \mathrm{~K} \cdot{ }^{27}$

In general, desorption of positive ions from surfaces under electron irradiation involves the production of holes in core levels of the substrate or adsorbates. Direct electronic excitation can also generate holes in the covalent bonds of surface species, for example, on the $\sigma$-bond of surface hydroxyl groups. The core holes can decay through many different mechanisms. One radiationless decay channel is Auger decay, through which at least two electrons can be removed from the system, leaving two localized holes in the valence band. For metal oxides, the holes are localized on oxygen atoms. Two holes localized on an oxygen atom which can be charge deficient can reverse the Madelung potential. The oxygen can then be removed as neutral atomic oxygen or $\mathrm{O}^{+}$. The Auger decay can also result in two holes on the $\sigma$-bond of a hydroxyl group, and the subsequent Coulomb repulsion can lead to desorption of $\mathrm{H}^{+}$.

From the energy diagram, the binding energies of $\mathrm{O} 2 \mathrm{~s}$ (21.8$23.5 \mathrm{eV})$, Ce $5 \mathrm{p}(18 \mathrm{eV})$, and $\mathrm{Gd} 5 \mathrm{p}(23 \mathrm{eV})$ core levels are close to the $22 \mathrm{eV}$ threshold for $\mathrm{H}^{+}$desorption. Therefore, $\mathrm{H}^{+}$ desorption may be associated with the ionization or hole production in these core levels and the presence of surface hydroxyl groups. Ce $5 \mathrm{p}(18.5 \mathrm{eV})$ ionization was found to be involved in the $\mathrm{ESD}^{28}$ and photon-stimulated desorption ${ }^{29}$ of $\mathrm{H}^{+}$from cerium oxides. Gd $5 \mathrm{p}$ excitation may contribute to $\mathrm{H}^{+}$desorption in a similar way. Because of the overlap of the O 2 s level with the Ce 5 p or Gd 5 p level, it is impossible to distinguish which type of hole contributes most to the $\mathrm{H}^{+}$ desorption. The $40 \mathrm{eV}$ yield change is very close to the binding energies of $\mathrm{Ce} 5 \mathrm{~s}(36.8 \mathrm{eV})$ and $\mathrm{Gd} 5 \mathrm{~s}(46.2 \mathrm{eV})$ levels. The interatomic Auger decay of the holes generated by electronic excitation at these $5 \mathrm{~s}$ levels is efficient in producing $\mathrm{H}^{+}$.

The $\mathrm{H}^{+}$desorption threshold data also suggests the presence of water on GDC surfaces at room temperature. In fact, the ESD threshold energies for $\mathrm{H}^{+}$desorption from ice are also found to be $22 \mathrm{eV}$ and $\sim 40 \mathrm{eV} .^{30,31}$ The $22 \mathrm{eV}$ threshold was assigned to configurationally mixed two-hole one-electron $\left(1 b_{1}\right)^{-2}\left(4 a_{1}\right)^{1}$ and $\left(3 \mathrm{a}_{1}\right)^{-1}\left(1 \mathrm{~b}_{1}\right)^{-1}\left(4 \mathrm{a}_{1}\right)^{1}$ final states of water and the $40 \mathrm{eV}$ threshold was assigned to $\left(3 \mathrm{a}_{1}\right)^{-2}\left(4 \mathrm{a}_{1}\right)^{1},\left(3 \mathrm{a}_{1}\right)^{-1}\left(1 \mathrm{~b}_{2}\right)^{-1}\left(4 \mathrm{a}_{1}\right)^{1}$, and $\left(1 b_{2}\right)^{-2}(4 a 1)^{1}$ states. $^{32}$ The nature of the yield change around $75 \mathrm{eV}$ is not clear at this stage and is under investigation. It could correlate with an excitation containing $2 \mathrm{a}_{1}{ }^{-2}$ character.

(III.c.2) Desorption of $\mathrm{O}^{+}$. Compared to $\mathrm{H}^{+}$desorption, the $22 \mathrm{eV}$ threshold for $\mathrm{O}^{+}$desorption is weak, so the contribution from hole production in the $\mathrm{O} 2 \mathrm{~s}$, Ce $5 \mathrm{p}$, or $\mathrm{Gd} 5 \mathrm{p}$ levels is limited. The yield change around $40 \mathrm{eV}$ is much stronger and can be related to the ionization of $\mathrm{Ce} 5 \mathrm{~s}$ or $\mathrm{Gd} 5 \mathrm{~s}$ levels. According to the Knotek-Feibelman model, the interatomic Auger decay of the $5 \mathrm{~s}$ holes can lead to the production of $\mathrm{O}^{+}$, as shown in Figure 5B. In general, a single Auger process can only remove two electrons from an oxygen atom. If the oxygen is in an $\mathrm{O}^{2-}$ oxidation state, then a third electron should be removed from the $\mathrm{O} 2 \mathrm{p}$ valence band in order to obtain $\mathrm{O}^{+}$. One way to realize the removal of the third electron is through a double Auger process which normally requires much higher excitation energy. However, if the involved oxygen anions are located close to oxygen vacancies, such as $\mathrm{V}_{\mathrm{a}}{ }^{2+}$ sites that have nominal charges less than 2 , then $\mathrm{O}^{+}$can be formed through a single Auger process. Interestingly, for $\mathrm{O}^{+}$desorption, a yield change around $150 \mathrm{eV}$, which is very close to the $\mathrm{Gd} 4 \mathrm{~d}$ level (143 eV), was observed. This yield change strongly suggests that the $\mathrm{O}^{+}$desorption is predominantly from $\mathrm{Gd}-\mathrm{O}$ rather than
$\mathrm{Ce}-\mathrm{O}$ bonds. Considering the association of oxygen vacancies with gadolinium atoms, the $\mathrm{O}^{+}$desorption is then closely related to the oxygen vacancies. Since Gd is rich in the grain boundary region of GDC, the dominant desorption sites should be located at the grain boundaries.

(III.c.3) Desorption of $\mathrm{H}_{3} \mathrm{O}^{+}$. Unlike the desorption of $\mathrm{H}^{+}$ and $\mathrm{O}^{+}$, only a threshold and a yield change were observed for $\mathrm{H}_{3} \mathrm{O}^{+}$at 22 and $\sim 40 \mathrm{eV}$, respectively. The mechanism of electron-stimulated $\mathrm{H}_{3} \mathrm{O}^{+}$desorption from oxide surfaces at room temperature is not yet established. Our model on the ESD of protonated water cluster ions $\left[\mathrm{H}\left(\mathrm{H}_{2} \mathrm{O}\right)_{n}\right]^{+}(n=1-8)$ from water ice surfaces showed that the process was initiated by positive charge localization on neighboring water molecules. ${ }^{31}$ For $\mathrm{H}_{3} \mathrm{O}^{+}$, there was also a channel involving reactive scattering of an energetic proton.

At room temperature, water can interact with the oxygen vacancies of metal oxides dissociatively and form hydroxyl groups. Water can also chemisorb to the surfaces. Although no water network is observed on these oxide surfaces at the room temperature, the presence of second layer water at a submonolayer coverage on reduced $\mathrm{CeO}_{2}$ (111) surface has been confirmed by Henderson et al. using temperature programmed desorption. ${ }^{33}$ We therefore propose that on GDC surfaces, the first layer of water molecules preferably adsorb to the oxygen vacancies, with one of the hydrogen atoms of water oriented away from the oxygen vacancy. The $\mathrm{O}-\mathrm{H}$ bond then is highly polarized by the positive charge of the oxygen vacancy, leading to the adsorption of the second layer of water on to the first layer with the formation of a hydrogen bond like interaction between the oxygen atom between water from the second layer and the polarized hydrogen atom of the first layer. The formation of $\left[\cdots \mathrm{H}^{\delta+} \cdot \cdots \mathrm{OH}_{2}\right]$, very close to the $\mathrm{H}_{3} \mathrm{O}^{+}$, will then serve as a precursor for $\mathrm{H}_{3} \mathrm{O}^{+}$desorption. The water can also adsorb to terminal $\mathrm{OH}$ groups leading perhaps forming a similar precursor.

Polarization of the $\mathrm{O}-\mathrm{H}$ bond of water by vacancies on GDC surfaces means the $\mathrm{O}-\mathrm{H}$ bond breakage is facilitated by water interaction with the surfaces. The oxygen atom from the water molecule can be incorporated into the lattice through formation of a hydroxyl group at the vacancy site. This process costs much less energy than the breakage of a $\mathrm{O}=\mathrm{O}$ double bond. This also means that the surface exchange process with water present in the feed gas should be higher. A recent study showed that a small amount of water vapor can enhance the surface oxygen exchange rate up to 1000 times on the surface of single-crystal yttria-stabilized zirconia (YSZ) at $873 \mathrm{~K} .{ }^{34}$ The water interaction with GDC surfaces can also account for the discrepancy of the activation energy for the oxygen surface exchange reaction, i.e., around $1 \mathrm{eV}$ for temperatures below 923 or $973 \mathrm{~K}$ and 2.4-3.3 $\mathrm{eV}$ at higher temperatures. ${ }^{12-15}$ At lower temperature, the water interaction with GDC is dominant, while at higher temperature oxygen reduction is rate limiting.

(III.d.1) Temperature Dependence of $\mathrm{H}_{3} \mathrm{O}^{+}$ESD. The influence of temperature on the ESD yields of $\mathrm{H}_{3} \mathrm{O}^{+}$is presented in Figure 6 . The data were taken from room temperature to $650 \mathrm{~K}$ during pulsed $400 \mathrm{eV}$ electron irradiation. When the sample temperature was increased from 300 to $360 \mathrm{~K}$, the $\mathrm{H}_{3} \mathrm{O}^{+} \mathrm{ESD}$ yields decreased sharply, most probably because of the complete desorption of the adsorbed sub-monolayer of water from the surface. For temperatures higher than $360 \mathrm{~K}$, the $\mathrm{H}_{3} \mathrm{O}^{+}$yields continued to decrease and the yields were around the detection limit.

Under $50 \mathrm{eV}$ electron beam irradiation, the $\mathrm{H}_{3} \mathrm{O}^{+}$data were taken after dosing 60 monolayer of water at liquid nitrogen temperature. In the temperature range from 100 to $550 \mathrm{~K}$, the 


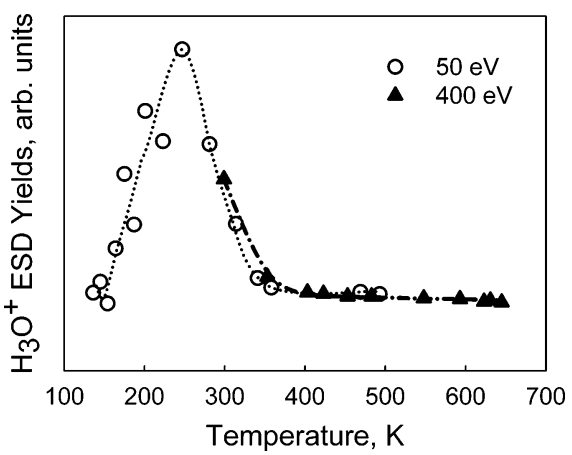

Figure 6. Dependence of $\mathrm{H}_{3} \mathrm{O}^{+}$ESD ion yields on sample temperature. The incident electron energy was $400 \mathrm{eV}$ with a pulse length of 200 $\mu \mathrm{s}$ and $50 \mathrm{eV}$ with a pulse length of $5 \mu \mathrm{s}$. The peak at $250 \mathrm{~K}$ indicates the involvement of chemisorbed water in the $\mathrm{H}_{3} \mathrm{O}^{+}$desorption.

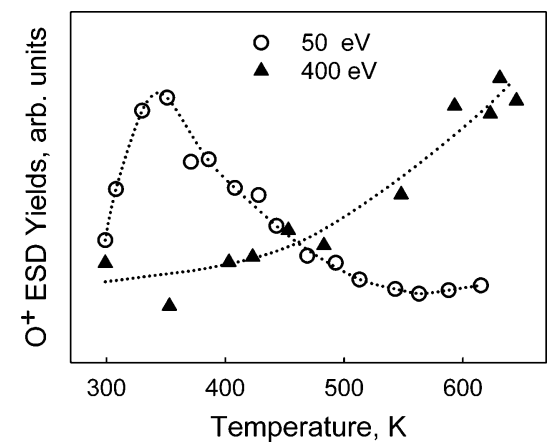

Figure 7. $\mathrm{O}^{+}$ESD ion yields as a function of sample temperature. The incident electron energy was $400 \mathrm{eV}$ with a pulse length of 200 $\mu \mathrm{s}$ and $50 \mathrm{eV}$ with a pulse length of $5 \mu \mathrm{s}$. Note, for temperatures greater than $360 \mathrm{~K}$, the $\mathrm{O}^{+}$yield increases with temperature for $400 \mathrm{eV}$ but decreases for $50 \mathrm{eV}$ electron bombardment.

$\mathrm{H}_{3} \mathrm{O}^{+}$ESD yield was minimum around $150 \mathrm{~K}$ and maximum around $250 \mathrm{~K}$. A temperature programmed desorption (TPD) study of water from a $500 \AA$ epitaxially grown $\mathrm{CeO}_{2}$ (111) surface shows peaks between 190 and $320 \mathrm{~K}^{33}$ The TPD spectra depended upon the coverage and the oxidation states of cerium ions or the population of oxygen vacancies. All adsorbed water molecules are desorbed around $400 \mathrm{~K}$ regardless of the coverage and surface condition. ${ }^{33}$ The $250 \mathrm{~K} \mathrm{ESD} \mathrm{H}_{3} \mathrm{O}^{+}$peak is quite close to the TPD water peak for a water coverage of 0.58 monolayer on a $\mathrm{CeO}_{2}$ (111) surface comprised of $\sim 33 \%$ monolayer of oxygen vacancies. This indicates the involvement of adsorbed sub-monolayer of water in the ESD of $\mathrm{H}_{3} \mathrm{O}^{+}$. At temperatures higher than $250 \mathrm{~K}$, the $\mathrm{H}_{3} \mathrm{O}^{+}$ESD yield drops quickly. At $360 \mathrm{~K}$, the $\mathrm{ESD} \mathrm{H}_{3} \mathrm{O}^{+}$yield is only $2 \%$ of that at $250 \mathrm{~K}$. This quick drop in ESD yields is therefore primarily due to water desorption.

(III.d.2) Temperature Dependence of $\mathrm{O}^{+} E S D$. The temperature dependence of $\mathrm{O}^{+}$ESD from GDC under the irradiation of a $50 \mathrm{eV}$ electron beam is presented in Figure 7. Experiments were carried out in the temperature range of $300-600 \mathrm{~K}$ without water dosing. Since the presence of water reduces the $\mathrm{O}^{+}$yield, we chose this temperature region to minimize the amount of adsorbed water. When the sample was heated, the $\mathrm{O}^{+} \mathrm{ESD}$ yields first increased, peaked around $360 \mathrm{~K}$, and then decreased. A different temperature dependency was observed for $400 \mathrm{eV}$ irradiation. Specifically, the yield simply increases monotonically with temperature.

A comparison of the ESD yields of $\mathrm{H}_{3} \mathrm{O}^{+}$and $\mathrm{O}^{+}$from GDC surface bombarded by $50 \mathrm{eV}$ electron beam is presented in Figure 8. It is interesting to note that the $\mathrm{O}^{+}$ESD yield peaked at the same temperature as the disappearance of $\mathrm{H}_{3} \mathrm{O}^{+}$, i.e., the

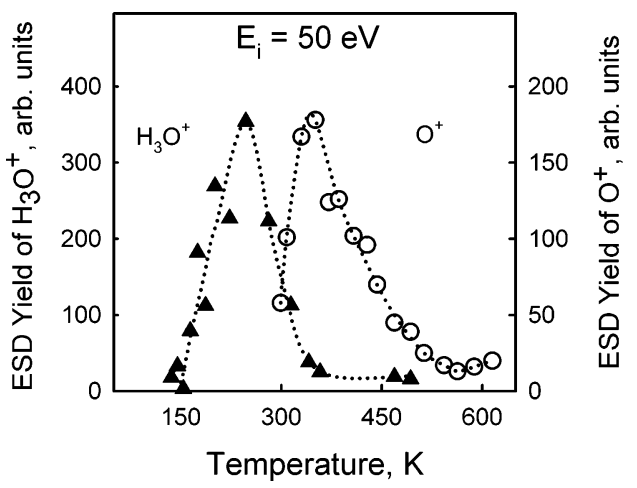

Figure 8. Dependence of $\mathrm{O}^{+}$and $\mathrm{H}_{3} \mathrm{O}^{+}$ESD ion yields on sample temperature. The incident electron energy was $50 \mathrm{eV}$, and the pulse length was $5 \mu \mathrm{s}$. The surface was dosed with $\sim 50$ monolayers of water at liquid nitrogen temperature before the $\mathrm{H}_{3} \mathrm{O}^{+}$desorption data were taken, but no water was dosed for $\mathrm{O}^{+}$data. Note that around $360 \mathrm{~K}$, the $\mathrm{O}^{+}$yields starts to decrease when the $\mathrm{H}_{3} \mathrm{O}^{+}$yields are below the detection limit.

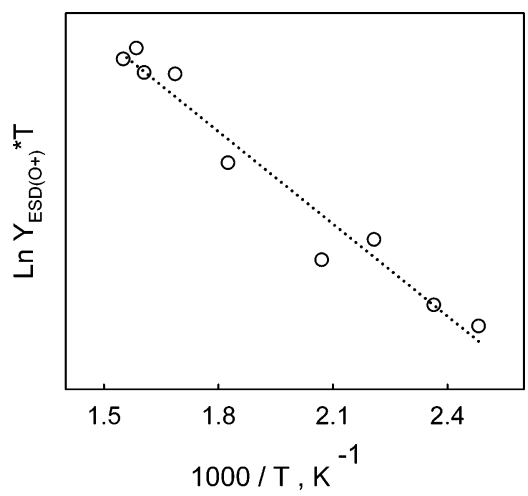

Figure 9. Arrhenius plot of $\mathrm{O}^{+} \mathrm{ESD}$ yield at $400 \mathrm{eV}$ in the temperature range of 400-600 K. The extracted activation energy for the ESD of $\mathrm{O}^{+}$is $0.21 \mathrm{eV}$, in agreement with the vacancy formation energy calculated by first-principles quantum mechanical simulation for ceria. ${ }^{8}$

temperature of total removal of chemisorbed water. This demonstrates, as stated above, that the chemisorbed water can influence the $\mathrm{O}^{+}$desorption.

(III.d.3) Temperature Effects. The threshold measurements have demonstrated that $\mathrm{O}^{+}$desorption is closely related to the presence of oxygen vacancies. It is therefore very interesting to explore the correlation between $\mathrm{O}^{+}$ESD and oxygen vacancy production on GDC surfaces. If we assume that the $\mathrm{O}^{+} \mathrm{ESD}$ yield $\left[Y_{\left.\operatorname{ESD}\left(\mathrm{O}^{+}\right)\right]}\right.$is proportional to the oxygen vacancy density, an Arrhenius plot of the logarithm of $Y_{\mathrm{ESD}\left(\mathrm{O}^{+}\right) \text {against } 1 / T \text { in }}$ the temperature range of 400-600 $\mathrm{K}$ should yield a linear relationship (see Figure 9). The activation energy calculated from this plot is $0.21 \mathrm{eV}$, close to the $0.26 \mathrm{eV}$ value found for the production of an oxygen vacancy near two $\mathrm{Ce}^{3+}$ in ceria as calculated by first-principles quantum mechanical simulations. ${ }^{8}$

According to Kilner et al., ${ }^{35}$ for doped fluorite oxides such as GDC, the vacancies induced by dopant ions are not free but bound to the dopant, forming vacancy-dopant pairs. In the temperature range of our experiment, the population of chargecarrying defects is determined by the thermodynamic equilibrium between the free defects and the associated vacancy-dopant pairs. At higher temperature, the number of free oxygen vacancies available for ionic conduction is greater. This suggests a potential correlation between the $\mathrm{O}^{+}$ESD yields and the ionic conductivity of GDC at low temperature.

The temperature dependence of $\mathrm{O}^{+}$yields under $50 \mathrm{eV}$ electron irradiation is completely different from that with 400 $\mathrm{eV}$ electrons. For temperatures greater than $360 \mathrm{~K}$, the mono- 
tonic decrease of the ion yields can be understood by charge trapping of the GDC surface. On the basis of our previous study on GDC, bombardment by $50 \mathrm{eV}$ electrons can charge the surface negatively, and these negative charges can decrease the cation desorption yields in at least two ways:

(1) The existence of the negative potential can increase the reneutralization and recapture rate of the desorbed ions and decrease the cation yields exponentially.

(2) The secondary electrons trapped by oxygen vacancies will subsequently increase the average negative charge on the oxygen anion and then decrease the probability of $\mathrm{O}^{+}$desorption resulting from Auger processes.

Therefore, the $50 \mathrm{eV}$ temperature dependence of $\mathrm{O}^{+} \mathrm{ESD}$ can be understood as a result of two competing trends, the increase of charge trapping with irradiation time and the increase of the equilibrium concentration of free oxygen vacancies with temperature. For temperatures below $360 \mathrm{~K}$, a trace amount of water is presented and charge buildup seems significantly less compared to the defect density increase caused by temperature elevation. Therefore, the overall $\mathrm{O}^{+}$desorption yield increases with temperature. When chemisorbed water is removed, the charge buildup becomes significant and the desorption of $\mathrm{O}^{+}$ decreases. In principle, at higher temperature, the GDC has higher electrical conductivity so the secondary electrons should not be trapped. However, within the temperature range of this experiment, the main contribution to GDC conductivity is oxygen vacancy diffusion instead of electron or hole migration. In this case, prolonged electron beam bombardment can cause the $\mathrm{O}^{+}$yields to decrease even at higher temperature. The decrease of $\mathrm{O}^{+}$yields with temperature also suggests that free oxygen vacancies may trap electrons more efficiently than vacancy associates.

\section{Conclusions}

Water interactions and vacancy production on gadoliniadoped ceria (GDC) surfaces were investigated by threshold and temperature-dependent electron-stimulated desorption measurements. $\mathrm{H}^{+}, \mathrm{H}_{3} \mathrm{O}^{+}$, and $\mathrm{O}^{+}$were the primary cationic desorption products with $\mathrm{H}^{+}$as the dominant channel. All of these cations have a $\sim 22 \mathrm{eV}$ threshold energy and an increased yield $\sim 40$ $\mathrm{eV}$. There is an additional change of the $\mathrm{H}^{+}$yield $\sim 75 \mathrm{eV}$ and the $\mathrm{O}^{+}$yield change $\sim 150 \mathrm{eV}$. The 40 and $150 \mathrm{eV}$ energies may suggest bond breaking of $\mathrm{Gd}-\mathrm{O}$ and the involvement of oxygen vacancies in $\mathrm{O}^{+}$desorption. The temperature dependence of cation ESD at different incident electron energies suggested preferential water adsorption on surface oxygen vacancy sites. The interaction of water with oxygen vacancies influences the desorption of $\mathrm{H}^{+}, \mathrm{O}^{+}$, and $\mathrm{H}_{3} \mathrm{O}^{+}$as well as the oxygen surface exchange reaction of GDC. An activation energy of $0.21 \mathrm{eV}$ for $\mathrm{O}^{+}$desorption was obtained from the temperature dependence of $\mathrm{O}^{+} \mathrm{ESD}$ at $400 \mathrm{eV}$. This energy is close to the energy needed for the production of an oxygen vacancy associated with two $\mathrm{Ce}^{3+}$ on ceria surfaces and therefore may indicate a correlation between the $\mathrm{O}^{+}$ESD yield and oxygen vacancy density on GDC surfaces.

Acknowledgment. This work was supported by the United States Department of Energy USDoE-NETL SECA Core Technology Program under Grant No. DE-FC26-02NT41572. The initial experiments also received support from the USDoE Nuclear Energy Research Initiative (NERI) under Grant No. DEFG03-00SF22207.

\section{References and Notes}

(1) Xia, C.; Liu, M. Solid State Ionics 2002, 152-153, 423.

(2) Steele, B. C. H. Solid State Ionics 2000, 129, 95.

(3) Inaba, H.; Tagawa, H. Solid State Ionics 1996, 83, 1.

(4) Xia, C.; Liu, M. Adv. Mater. (Weinheim, Ger.) 2002, 14, 521.

(5) Minh, N. Q. J. Am. Ceram. Soc. 1993, 76, 563.

(6) Norenberg, H.; Briggs, G. A. D. Surf. Sci. 1999, 433-435, 127.

(7) Norenberg, H.; Briggs, G. A. D. Phys. Rev. Lett. 1997, 79, 4222

(8) Skorodumova, N. V.; Simak, S. I.; Lundqvist, B. I.; Abrikosov, I. A.; Johansson, B. Phys. Rev. Lett. 2002, 89, 166601/1.

(9) Inaba, H.; Sagawa, R.; Hayashi, H.; Kawamura, K. Solid State Ionics 1999, 122, 95

(10) Lei, Y.; Ito, Y.; Browning, N. D.; Mazanec, T. J. J. Am. Ceram. Soc. 2002, 85, 2359.

(11) Petot-Ervas, G.; Petot, C.; Zientara, D.; Kusinski, J. Mater. Chem. Phys. 2003, 81, 305.

(12) Manning, P. S.; Sirman, J. D.; Kilner, J. A. Solid State Ionics 1996, 93,125

(13) Ruiz-Trejo, E.; Sirman, J. D.; Baikov, Y. M.; Kilner, J. A. Solid State Ionics 1998, 113-115, 565.

(14) Lane, J. A.; Kilner, J. A. Solid State Ionics 2000, 136-137, 997.

(15) Lane, J. A.; Kilner, J. A. Solid State Ionics 2000, 136-137, 927.

(16) Ramsier, R. D.; Yates, J. T., Jr. Surf. Sci. Rep. 1991, 12, 243.

(17) de Segovia, J. L.; Williams, E. M. Chem. Phys. Solid Surf. 2001, $9,608$.

(18) Knotek, M. L.; Feibelman, P. J. Phys. Rev. Lett. 1978, 40, 964.

(19) Ramaker, D. E. J. Vac. Sci. Technol., A 1983, 1, 1137.

(20) Chen, H.; Chen, Y.; Aleksandrov, A.; Dong, J.; Liu, M.; Orlando, T. M. Appl. Surf. Sci. 2005, 243, 168.

(21) Song, H. Z.; Wang, H. B.; Zha, S. W.; Peng, D. K.; Meng, G. Y. Solid State Ionics 2003, 156, 249.

(22) Raiser, D.; Deville, J. P. J. Electron Spectrosc. Relat. Phenom. 1991 $57,91$.

(23) Wandelt, K.; Brundle, C. R. Surf. Sci. 1985, 157, 162.

(24) Emeline, A. V.; Kataeva, G. V.; Ryabchuk, V. K.; Serpone, N. J. Phys. Chem. B 1999, 103, 9190.

(25) Teterin, Yu. A.; Teterin, A. Yu.; Lebedev, A. M.; Utkin, I. O. Radiochemistry 1998, 40, 101.

(26) Patsalas, P.; Logthetidis, S.; Sygellou, S.; Kennou, S. Phys. Rev. B 2003, 68, 035104

(27) Kundakovic, L.; Mullins, D. R.; Overbury, S. H. Surf. Sci. 2000, $457,51$.

(28) Loubriel, G.; Knotek, M. L.; Stulen, R. H.; Koel, B. E.; Parks, C. C. J. Vac. Sci. Technol., A 1983, 1, 1145 .

(29) Koel, B. E.; Loubriel, G. M.; Knotek, M. L.; Stulen, R. H.; Rosenberg, R. A.; Parks, C. C. Phys. Rev. B 1982, 25, 5551.

(30) Sieger, M. T.; Simpson, W. C.; Orlando, T. M. Phys. Rev. B 1997, $56,4925$.

(31) Herring, J.; Aleksandrov, A.; Orlando, T. M. Phys. Rev. Lett. 2004, $92,187602$.

(32) Ramaker, D. E. Chem. Phys. 1983, 80, 183

(33) Henderson, M. A.; Perkins, C. L.; Engelhard, M. H.; Thevuthasan, S.; Peden, C. H. F. Surf. Sci. 2003, 526, 1.

(34) Sakai, N.; Yamaji, K.; Horita, T.; Xiong, Y. P.; Kishimoto, H.; Yokokawa, H. J. Electrochem. Soc. 2003, 150, A689.

(35) Kilner, J. A., Steele, B. C. H., Sorensen, O. T., Eds. Nonstoichiometric Oxides 1981, 233. 